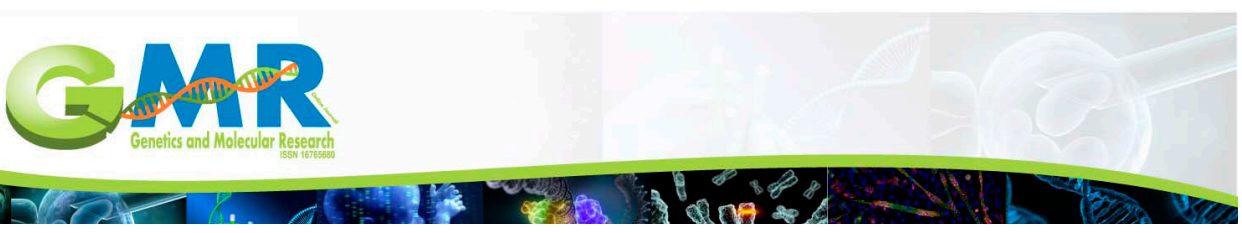

\title{
5-Fluorouracil induces apoptosis of colorectal cancer cells
}

\author{
J.T. Zhang ${ }^{1}$, W.L. Zhou' ${ }^{2}$, C. He ${ }^{3}$, T. Liu', C.Y. Li ${ }^{1}$ and L. Wang ${ }^{1}$ \\ ${ }^{1}$ Department of Colorectal and Anal Surgery, First Affiliated Hospital of Jilin University, \\ Changchun, China \\ ${ }^{2}$ Department of Neonatology, First Affiliated Hospital of Jilin University, Changchun, \\ China \\ ${ }^{3}$ Department of Nerve Trauma Surgery, First Affiliated Hospital of Jilin University, \\ Changchun, China \\ Corresponding author: L. Wang \\ E-mail: leiwang1850@163.com \\ Genet. Mol. Res. 15 (1): gmr.15017326 \\ Received September 14, 2015 \\ Accepted December 4, 2015 \\ Published March 4, 2016 \\ DOI http://dx.doi.org/10.4238/gmr.15017326
}

ABSTRACT. 5-Fluorouracil (5-FU) is widely used in chemotherapy for treatment of colorectal cancer. Leucine-rich repeat-containing $G$ protein-coupled receptor (LGR) is known to participate in the occurrence and development of breast cancer by regulating the rebirth of tumor vessels. This study aimed to explore the proliferation and apoptosis of HCT116 colorectal cancer cells treated with 5-FU and related molecular mechanisms. $5-\mathrm{FU}(20 \mu \mathrm{g} / \mathrm{mL})$ was used to treat cultured HCT116 cells. An MTT test, flow cytometry, and colony formation assays were used to examine the proliferation and apoptosis of HCT116 cells. Western blotting was applied to detect the expression of the LGR4 protein in HCT116 cells. Small interference RNA or over-expression techniques were used to manipulate LGR4 expression in HCT116 cells and describe the proliferation and apoptosis of HCT116 treated with 5-FU. A dosage of $20 \mu \mathrm{g} / \mathrm{mL} 5-\mathrm{FU}$ resulted in a significant decrease in the proliferation and apoptosis of HCT116 cells and significantly decreased expression levels of LGR4. The specific gene silence or over-expression of LGR4 in HCT116 cells 
increased and decreased the levels of apoptosis in HCT116, respectively. 5 -FU induces apoptosis of colorectal cancer cells and inhibits proliferation by suppressing LGR4 proteins.

Key words: 5-Fluorouracil; Malignant proliferation; Cell apoptosis; Leucine-rich repeat-containing G protein-coupled receptor 4 (LGR4) protein; Colorectal cancer cell HCT116

\section{INTRODUCTION}

Colorectal cancer, the third most prevalent gastrointestinal cancer (following gastric and esophageal cancer), decreases the patient's quality of life and constitutes a public health issue (Peng et al., 2015). Colorectal cancer often develops in the junction of the sigmoid colon and rectum in patients between 45 and 55 years of age. The incidence ratio in men and women varies from 2:1 to 3:1 (Peng et al., 2015). Patients often experience indigestion, abdominal distention and pain, edema, jaundice, and supraclavicular lymph node swelling (Peng et al., 2015). Treatments for colorectal cancer include surgical resection, chemotherapy, immunotherapy, or a combination of these methods (Ogata et al., 2015).

Surgical treatment is still the most effective and primary choice. However, its effectiveness is limited in elderly patients or cardiovascular disease patients, for whom chemotherapy is an alternative choice (Ogata et al., 2015). 5-Fluorouracil (5-FU) is the most widely used chemotherapy drug for the treatment of colorectal cancer (Ogata et al., 2015) and is an effective cancer treatment (Yashima et al., 2015). 5-FU is known to inhibit the growth and proliferation of breast cancer cells and induces cell apoptosis (Wang et al., 2015). However, the molecular mechanisms of 5-FU in resisting colorectal cancer have not been studied. LGR4 is a Wnt signal transduction pathway receptor and belongs to the RSPO family (Wang et al., 2015). The LGR4 protein participates in the occurrence and development of breast cancer by regulating angiogenesis (Liang et al., 2015).

Studies have shown that LGR4-positive tumor cells have a strong proliferative ability, making it an important marker of tumor cell proliferation and migration. Therefore, knockout of the LGR4 gene in tumor cells may improve the treatment efficacy of chemotherapy.

Because the molecular mechanism of LGR4 in colorectal cancer has not been determined, this study used HCT116 cells to investigate the effects of 5-FU on the development, proliferation, and apoptosis of HCT116 cells and its related molecular mechanisms.

\section{MATERIAL AND METHODS}

\section{Reagents and cells}

5-FU was purchased from Sigma (St. Louis, MO, USA). It was dissolved in sterilized double-steamed water to a concentration of $50 \mathrm{~g} / \mathrm{mL}$ and was stored at $-80^{\circ} \mathrm{C}$ until use. Both mouse monoclonal anti-LGR4 antibody and goat anti-mouse IgG secondary antibody conjugated with horseradish peroxidase were purchased from Santa Cruz (Dallas, TX, USA). Mouse monoclonal anti-actin antibody was purchased from Sigma. Both Dulbecco's modified Eagle's medium (DMEM) and fetal bovine serum (FBS) were purchased from Sigma. Colorectal cancer HCT116 cells were obtained from American-Type Culture Collection (ATCC). 


\section{Cell culture}

As previously reported (Monavari et al., 2014), HCT116 cells were re-suspended in DMEM (containing $10 \% \mathrm{FBS}$ ) after recovery, and were cultured at $37^{\circ} \mathrm{C}$ in a $5 \% \mathrm{CO}_{2}$ chamber for $24 \mathrm{~h}$. 5 -FU $(20 \mu \mathrm{g} / \mathrm{mL})$ was added, and an equal volume of sterilized water was applied in the control group. After $48 \mathrm{~h}$, all cells were collected for western blot and colony formation tests.

\section{MTT test}

As previously reported, the MTT assay was adopted to describe the proliferation ability of cultured HCT116 cells in each group (Damnjanovic et al., 2015). In brief, cells in each group were inoculated on a 96-well plate (9000 cells/well). After 72-h incubation, $5 \mathrm{mg} / \mathrm{mL}$ MTT reaction solution (blue-violet crystal methyl formazan) was added for 4-h color development. DMSO (160 $\mu \mathrm{L}$ ) was added to each well to stop the reaction, followed by a 6-min rinse. An enzyme-linked immunoassay instrument measured absorbance values at $492 \mathrm{~nm}$. The cell growth curve was plotted using the optical absorbance value and standard curve.

\section{Flow cytometry}

Flow cytometry was used to detect the apoptosis of HCT116 cells as previously reported (Riquier et al., 2015). Cells $(80,000)$ were re-suspended in $250 \mu \mathrm{L}$ combination reagent of AnnexinV-FITC, followed by the addition of $5 \mu \mathrm{L}$ Annexin-V-FITC reaction reagent. The mixture was developed in the dark at room temperature $\left(23^{\circ} \mathrm{C}\right)$ for $20 \mathrm{~min}$ (AlKurashi et al., 2011). Flow cytometry was used to describe the apoptosis level using 488 and $625 \mathrm{~nm}$ exciting and absorbing wavelengths, respectively.

\section{Colony formation test}

We further examined the colony formation capacity of cultured HCT116 cells following established procedures (Diensthuber et al., 2014). First, cells were serially diluted to $0,5,20,80$, and 160 cells (Sempere et al., 2014). All cells were then inoculated onto soft agar plates, which were then cultured in a $5 \% \mathrm{CO}_{2}$ incubator at $37^{\circ} \mathrm{C}$ for 14 days. After the formation of colonies, culture medium was removed, followed by fixation using 100\% methanol at room temperature for $20 \mathrm{~min}$. Giemsa reagent was used to stain the cells for $20 \mathrm{~min}$. The number of cell colonies was counted and recorded.

\section{Western blot}

According to the established protocol (Yan et al., 2015), HCT116 cells were collected for the quantification of the LGR4 protein level (Fachal et al., 2014). Cells were first lysed in buffer for $30 \mathrm{~min}$ on ice and were centrifuged to collect proteins. Using anti-LGR4 and anti-actin antibodies, membranes were incubated for $2 \mathrm{~h}$, followed by incubation with the secondary antibody. After gentle washing, horseradish peroxidase reagents were used for color development. Images were captured and analyzed for relative LGR4 levels in each group. 


\section{LGR4 siRNA transfection}

HCT116 cells were inoculated on 96-well plates. Culture medium was changed 1 day before transfection. LGR4 siRNA (5'-GGTTA CCTTG TTACG ACTTA GAGTT TGATC CTGGC TCA3') was diluted in serum-free DMEM at $250 \mathrm{nM}$. siRNA was gently mixed with transfection reagent and incubated at room temperature for $30 \mathrm{~min}$. Liposome mixtures were added on 96-well plates, which were then incubated in a $\mathrm{CO}_{2}$ chamber at $37^{\circ} \mathrm{C}$ for $36 \mathrm{~h}$. Further tests were performed to examine the status of cell apoptosis (lonov et al., 2015).

\section{Statistical analysis}

SPSS 16.0 was used to process all data, which are reported as means \pm standard deviation (SD) (Oliveira et al., 2014). One-way analysis of variance was adopted in multiple group comparisons (Dzmitruk et al., 2015). P < 0.05 was defined as having statistical significance.

\section{RESULTS}

\section{Growth of HCT116 cells was inhibited by 5 -FU}

As shown in Figure 1, after the addition of $20 \mu \mathrm{g} / \mathrm{mL} 5-\mathrm{FU}$, the growth of HCT116 cells was significantly inhibited $(P=0.029)$.

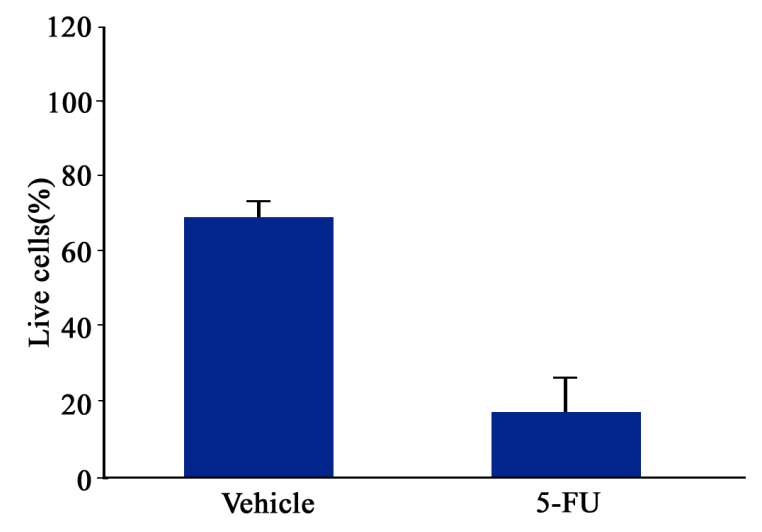

Figure 1. Growth of HCT116 cells inhibited by treatment with 5-FU.

\section{HCT116 cells treated with 5-FU exhibited apoptosis}

After treatment with $20 \mu \mathrm{g} / \mathrm{mL} 5-\mathrm{FU}, \mathrm{HCT} 116$ cells exhibited significant apoptosis (as shown by phosphatidylserine valgus $(P=0.0001$; Figure 2$)$.

\section{HCT116 cell proliferation was inhibited by treatment with 5-FU}

As shown in Figure 3, HCT116 cells treated with $20 \mu \mathrm{g} / \mathrm{mL} 5-\mathrm{FU}$ formed fewer colonies ( $\mathrm{P}$ $=0.0078)$, suggesting impaired proliferation capacity. 

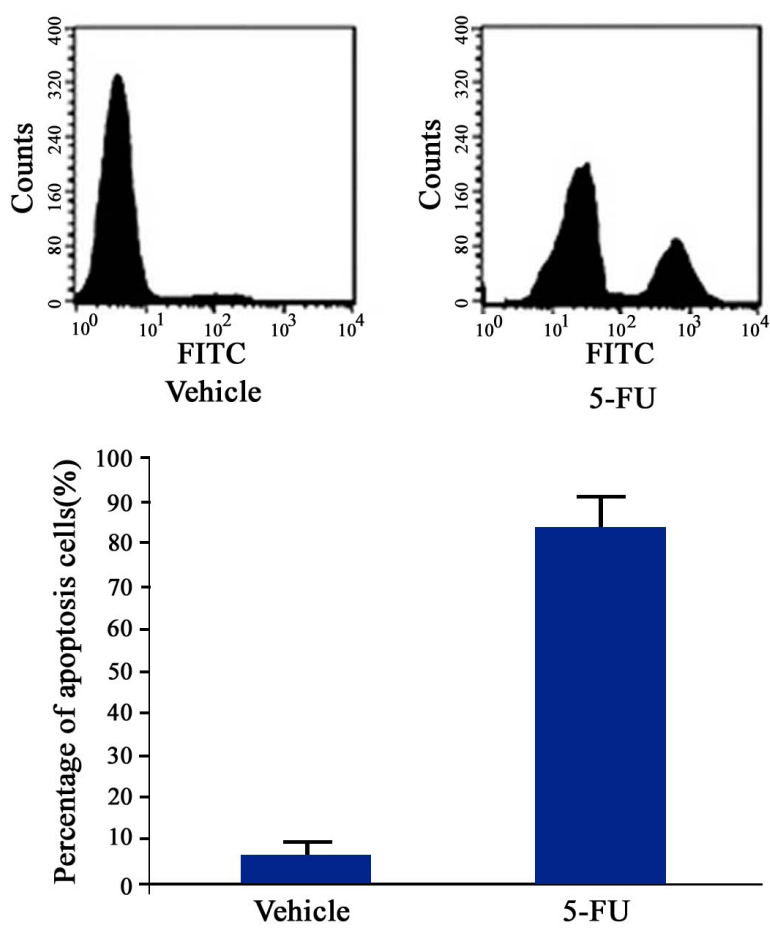

Figure 2. HCT116 cells exhibited apoptosis after treatment with 5-FU.

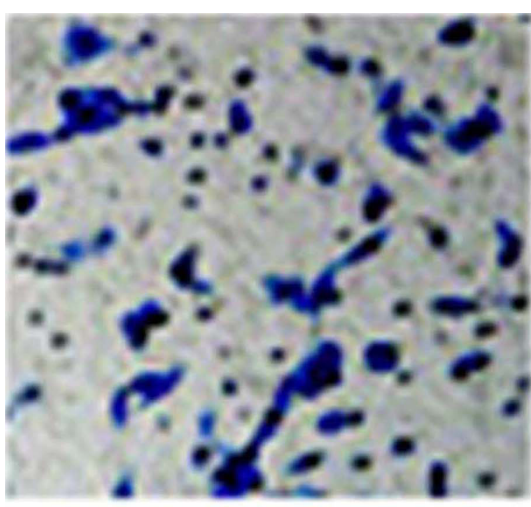

Vehicle

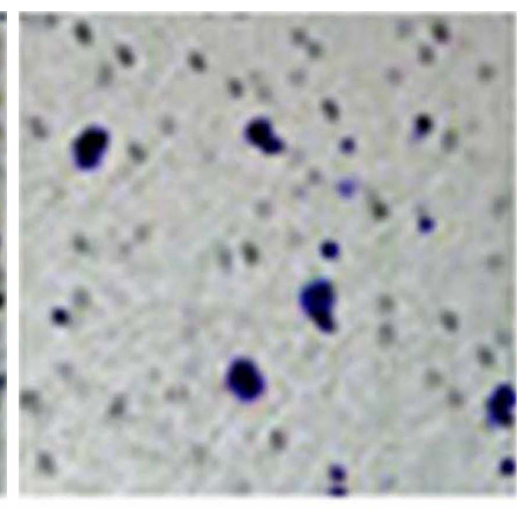

5-FU

Figure 3. Treatment with $20 \mu \mathrm{g} / \mathrm{mL}$ 5-FU inhibited HCT116 cell colony formation.

\section{LGR4 protein expression levels in HCT116 cells}

The LGR4 protein was expressed in HCT116 cells (Figure 4). After treatment with $20 \mu \mathrm{g} /$ $\mathrm{mL} 5-\mathrm{FU}$, the expression level of the LGR4 protein in HCT116 cells was significantly reduced $(\mathrm{P}=$ 0.017 ; Figure 4). 

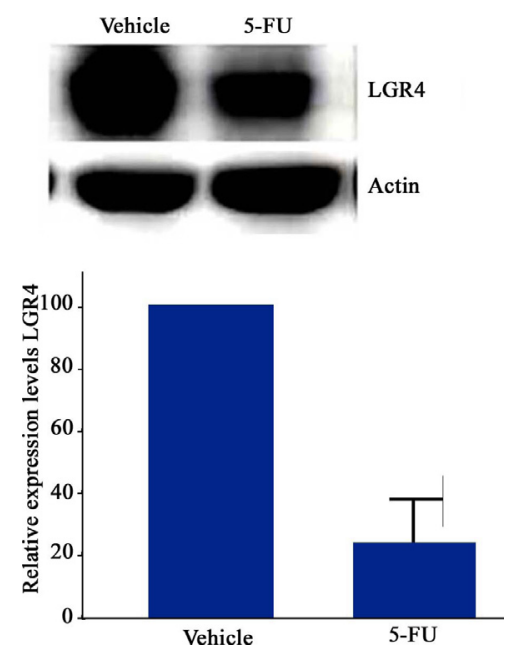

Figure 4. Expression level of the LGR4 protein in HCT116 cells.

\section{LGR4 gene silencing enhanced the 5-FU sensitivity of HCT116 cells}

As shown in Figure 5, after the intervention of $L G R 4$ gene expression using siRNA, the application of $5-F U$ significantly increased the cell apoptosis level $(P=0.031)$. These results indicate that the sensitivity of HCT116 cells to 5-FU was enhanced by silencing the LGR4 gene.
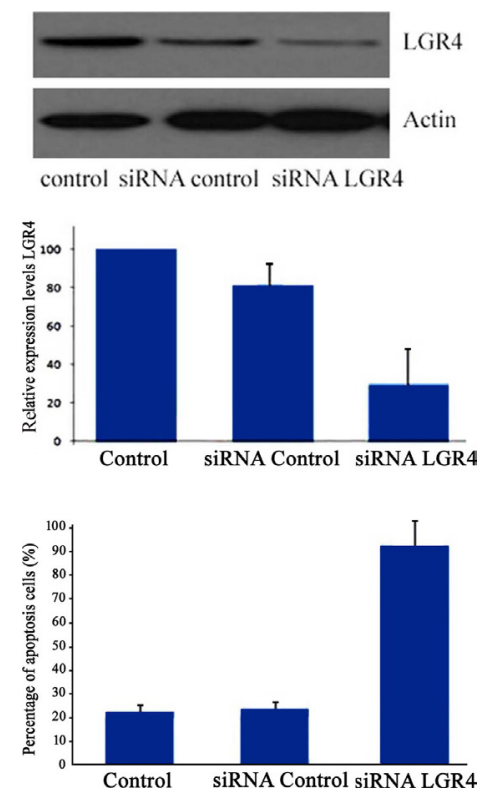

Figure 5. LGR4 silencing enhanced the sensitivity of HCT116 cells to 5-FU (Note: all three groups are processed with $2 \mu \mathrm{g} / \mathrm{mL} 5-\mathrm{FU})$. 


\section{Over-expression of LGR4 decreased the sensitivity of HCT116 cells to 5-FU}

As shown in Figure 6, after transfection with LGR4, cells treated with $2 \mu \mathrm{g} / \mathrm{mL} 5$-FU exhibited less apoptosis $(P=0.031)$.
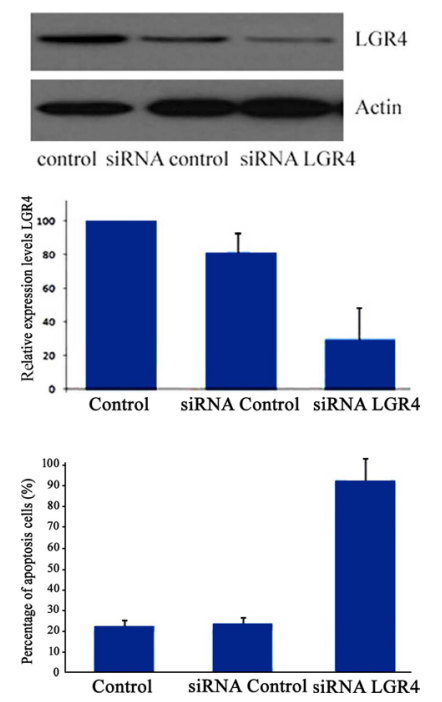

Figure 6. Over-expression of $L G R 4$ weakened the sensitivity of HCT116 cells to 5-FU.

\section{DISCUSSION}

The common digestive system cancer (Tristante et al., 2015), colorectal cancer, is increasing in incidence despite improvements in living standards (Cho et al., 2015). Therefore, the molecular mechanisms of the growth and apoptosis of colorectal cancer have clinical significance.

At present, the chemotherapy drugs used for treatment of colorectal cancer fall into six major categories, namely bevacizumab, irinotecan, capecitabine, 5-FU, oxaliplatin, and cetuximab. Each kind of drug has a unique molecular mechanism and clinical efficacy. Oxaliplatin and 5-FU are commonly recommended in clinical practice because of their less severe side effects.

5-FU exerts its anti-tumor action via inducing cellular apoptosis. However, the potential molecular targets of 5-FU have yet to be studied. Therefore, we explored the possible regulatory mechanism of 5-FU on HCT116 cells. After treatment with $5-\mathrm{FU}$, both growth capacity $(\mathrm{P}=0.029)$ and proliferative capacity $(\mathrm{P}=0.0078)$ of HCT116 cells decreased significantly. This is consistent with previous research (Siyar Ekinci et al., 2015).

LGR (Siyar Ekinci et al., 2015) is a Wnt signal transduction pathway receptor (Fachal et al., 2014) and belongs to the RS5-PO family (Haack et al., 2015). LGR participates in the occurrence and development of breast cancer. However, whether the LGR4 protein is involved in the growth and proliferation of colorectal cancer cells is not clear. This study showed that after treatment with 5-FU, the expression levels of LGR4 in HCT116 cells decreased. This was further supported by the silence or over-expression of the LGR4 levels and related increased or decreased levels of apoptosis.

The therapeutic effect of 5-FU is closely associated with the LGR4 protein. First, our results have shown that after 5-FU treatment, the expression level of the LGR4 protein in HCT116 
cells significantly decreased. Second, siRNA intervention of the LGR4 gene increased the sensitivity of cells to 5-FU, as shown by higher apoptotic levels (such as phosphatidylserine valgus). Third, overexpression of LGR4 inhibited 5-FU-induced cell apoptosis. These results demonstrated that LGR4 played an important role in the treatment efficacy of 5-FU in colorectal cancer cells. Meanwhile, these results also suggested the potency of the LGR4 protein as a drug target for future cancer treatment.

Follow-up studies should be carried out. First, clinical samples of colorectal cancers at different stages should be analyzed for the expression levels of the LGR4 protein using western blotting to further support our in vitro model. Second, more tumor samples from patients treated with different chemotherapy drugs should be analyzed for LGR4 protein levels using western blot, in an attempt to further explore the potency of LGR4 protein as a novel cancer marker. Moreover, colorectal tumor cells with LGR4 gene knockouts or knockdowns should be injected into nude mice, after receiving 5-FU treatment. This should help us to better evaluate the treatment efficacy of combing chemotherapy and the genetic approach. These studies could help show the clinical significance of treatment.

In clinical practice, it is common to observe drug resistance to 5-FU in colorectal cancer patients. In order to effectively eliminate cancer cells, clinicians need to increase the drug dose. However, this may cause various adverse effects, such as hair loss, nausea, diarrhea, and dermatitis (Takii et al., 2013). To minimize such side effects from 5-FU treatment, it is necessary to increase the sensitivity of cancer cells to 5-FU. Our results showed that deceasing LGR4 repression might elevate the sensitivity of cancer cells to 5-FU and help to improve the efficacy in the clinic.

In summary, 5-FU induces apoptosis of colorectal cancer cells and inhibits its malignant proliferation by decreasing LGR4 proteins, which may work as a potential drug target.

\section{REFERENCES}

AlKurashi M, Eastick FA, Kuchipudi SV, Rauch C, et al. (2011). Influence of culture medium pH on internalization, growth and phenotypic plasticity of Neospora caninum. Vet. Parasitol. 177: 267-274. http://dx.doi.org/10.1016/j.vetpar.2010.11.053

Cho H, Nishiike S, Yamamoto Y, Takenaka Y, et al. (2015). Docetaxel, cisplatin, and fluorouracil for patients with inoperable recurrent or metastatic head and neck squamous cell carcinoma. Auris Nasus Larynx 42: 396-400. http://dx.doi. org/10.1016/j.anl.2015.02.009

Damnjanovic I, Najman S, Stojanovic S, Stojanovic D, et al. (2015). Crosstalk between possible cytostatic and antiinflammatory potential of ketoprofen in the treatment of culture of colon and cervix cancer cell lines. Bratisl. Lek Listy (Tlacene Vyd) 116: 227-232.

Diensthuber M, Zecha V, Wagenblast J, Arnhold S, et al. (2014). Clonal colony formation from spiral ganglion stem cells. Neuroreport 25: 1129-1135. http://dx.doi.org/10.1097/WNR.0000000000000240

Dzmitruk V, Szulc A, Shcharbin D, Janaszewska A, et al. (2015). Anticancer siRNA cocktails as a novel tool to treat cancer cells Part (B). Efficiency of pharmacological action. Int. J. Pharm. 485: 288-294. http://dx.doi.org/10.1016/j.ijpharm.2015.03.034

Fachal L, Blanco A, Santamariña M, Carracedo A, et al. (2014). Large genomic rearrangements of BRCA1 and BRCA2 among patients referred for genetic analysis in Galicia (NW Spain): delimitation and mechanism of three novel BRCA1 rearrangements. PLoS One 9: e93306. http://dx.doi.org/10.1371/journal.pone.0093306

Haack F, Lemcke H, Ewald R, Rharass T, et al. (2015). Spatio-temporal model of endogenous ROS and raft-dependent WNT/ beta-catenin signaling driving cell fate commitment in human neural progenitor cells. PLOS Comput. Biol. 11: e1004106. http://dx.doi.org/10.1371/journal.pcbi.1004106

Ionov M, Lazniewska J, Dzmitruk V, Halets I, et al. (2015). Anticancer siRNA cocktails as a novel tool to treat cancer cells. Part (A). Mechanisms of interaction. Int. J. Pharm. 485: 261-269. http://dx.doi.org/10.1016/j.ijpharm.2015.03.024

Liang F, Yue J, Wang J, Zhang L, et al. (2015). GPCR48/LGR4 promotes tumorigenesis of prostate cancer via PI3K/Akt signaling pathway. Med. Oncol. 32: 49. http://dx.doi.org/10.1007/s12032-015-0486-1

Monavari SH, Mirzaei Parsa MJ, Bolouri B, Ebrahimi SA, et al. (2014). The inhibitory effect of Acyclovir loaded nano-niosomes against herpes simplex virus type-1 in cell culture. Med. J. Islam. Repub. Iran 28: 99.

Ogata Y, Matono K, Tsuda H, Ushijima M, et al. (2015). Randomized phase II study of 5-fluorouracil hepatic arterial infusion with or without antineoplastons as an adjuvant therapy after hepatectomy for liver metastases from colorectal cancer. PLoS One 10: e0120064. http://dx.doi.org/10.1371/journal.pone.0120064 
Oliveira DC, Silva CB, Muniz BV, Volpato MC, et al. (2014). Effect of 4-(N,N-dimethylamino)phenethyl alcohol on degree of conversion and cytotoxicity of photo-polymerized CQ-based resin composites. Braz. Dent. J. 25: 538-542. http://dx.doi. org/10.1590/0103-6440201300113

Peng H, Li TW, Yang H, Moyer MP, et al. (2015). Methionine adenosyltransferase 2B-GIT1 complex serves as a scaffold to regulate Ras/Raf/MEK1/2 activity in human liver and colon cancer cells. Am. J. Pathol. 185: 1135-1144. http://dx.doi. org/10.1016/j.ajpath.2014.12.016

Riquier H, Abel D, Wera AC, Heuskin AC, et al. (2015). Effects of alpha particle and proton beam irradiation as putative crosstalk between A549 cancer cells and the endothelial cells in a co-culture system. Cancers (Basel) 7: 481-502. http://dx.doi. org/10.3390/cancers7010481

Sempere JM, Martinez-Peinado P, Arribas MI, Reig JA, et al. (2014). Single cell-derived clones from human adipose stem cells present different immunomodulatory properties. Clin. Exp. Immunol. 176: 255-265. http://dx.doi.org/10.1111/cei.12270

Siyar Ekinci A, Demirci U, Cakmak Oksuzoglu B, Ozturk A, et al. (2015). KRAS discordance between primary and metastatic tumor in patients with metastatic colorectal carcinoma. J. BUON 20: 128-135.

Takii Y, Yamazaki T, Okada T, Tani T, et al.; Niigata Colorectal cancer Chemotherapy Study Group (2013). Phase I/II trial of irinotecan and S-1 combination chemotherapy as a second-line treatment for advanced colorectal cancer. Chemotherapy 59: 338-343.

Tristante E, Martínez CM, Jiménez S, Mora L, et al. (2015). Association of a characteristic membrane pattern of annexin A2 with high invasiveness and nodal status in colon adenocarcinoma. Transl. Res. 166: 196-206. http://dx.doi.org/10.1016/j. $\underline{\operatorname{trsl} .2015 .02 .006}$

Wang T, Huang B, Guo R, Ma J, et al. (2015). A let-7b binding site SNP in the 3 $\phi$-UTR of the Bcl-xL gene enhances resistance to 5-fluorouracil and doxorubicin in breast cancer cells. Oncol. Lett. 9: 1907-1911.

Yan HC, Xu J, Fang LS, Qiu YY, et al. (2015). Ectopic expression of the WWOX gene suppresses stemness of human ovarian cancer stem cells. Oncol. Lett. 9: 1614-1620.

Yashima Y, Sato S, Kawai T, Sugimoto T, et al. (2015). Intraarterial 5-fluorouracil and interferon therapy is safe and effective for nonresectable biliary tract adenocarcinoma. Hepatol. Int. 9: 142-148. http://dx.doi.org/10.1007/s12072-014-9583-z 